\title{
IMMUNOEXPRESSION OF KI-67 IN PULMONARY HYPOPLASIA
}

\author{
Monika Dzieniecka, Karolina Krystosiak, Andrzej Kulig
}

Department of Clinical Pathology, Research Institute of the Polish Mother's Memorial Hospital, Lodz, Poland

\begin{abstract}
Adequate pulmonary development at birth is the major determinant of postnatal outcome in the perinatal period. Lung hypoplasia is a poorly defined condition. The aim of this study was to investigate expression of Ki-67 in human fetuses with pulmonary hypoplasia compared to fetuses without pulmonary pathology and malformations of other organs used as controls. The analysis comprised 149 formalin-fixed and paraffin-embedded tissue sections from the files of the Clinical Pathology Department of the Research Institute of Polish Mother's Memorial Hospital in Lodz. Tissue sections obtained from lungs during autopsies were divided into two groups. In our studies immunohistochemistry was performed using antibody against Ki-67 as a cell proliferation marker for evaluation of growth fraction in the fetal and neonatal human lungs. The results presented in our study showed higher expression of growth fraction in the control group as compared to study subjects in all stages of lung development. Values of Ki-67 positive cells in the saccular stage of lung development were lower than in the canalicular and alveolar phase in both study and control groups. In conclusion, our results indicate their usefulness to understand better etiology of pulmonary hypoplasia and may be helpful in identifying the most appropriate moment for prenatal interventions.
\end{abstract}

Key words: pulmonary hypoplasia, growth fraction, Ki-67 immunoexpression.

\section{Introduction}

Adequate pulmonary development at birth is the major determinant of postnatal outcome in the perinatal period. Assessment of lung growth is often the most important component of the perinatal autopsy. Despite prenatal diagnosis and new postnatal treatment strategies, the mortality rate of infants with pulmonary hypoplasia is still high.

Pulmonary hypoplasia is a poorly defined condition seen in approximately $10-26 \%$ of neonatal autopsies [1-4]. This entity may be either unilateral (mostly related to congenital diaphragmatic hernia) or bilateral. Five independent risk factors for this condition have been described: hydrops fetalis, renal malformations, congenital diaphragmatic hernia/omphalocele, skeletal anomalies and abnormalities of amniotic fluid volume [5]. There is a spectrum of severity of this condition usually proportional to the severity of the underlying le- sion. Clinical manifestation of pulmonary hypoplasia in neonates ranges from severe respiratory failure leading to neonatal death to respiratory insufficiency. The radiological recognition of hypoplastic lung is difficult but possible using three-dimensional ultrasonography or magnetic resonance imaging [6-11].

Two histological patterns in pulmonary hypoplasia have been described, although these are not always sharply delineated. In the first pattern, the lungs are poorly grown, but maturation is appropriate for the gestation age of the infant. In the second, the lungs are poorly grown and appear immature for the gestation age (delay in development of blood-air barriers, delay in epithelial maturation, lack of elastic tissue development and low concentration of lung phospholipids). Poor maturation is especially associated with oligohydramnios-related hypoplasia [12-17].

Because histological findings lack specificity, many pathological criteria of lung hypoplasia have 
been established. These include: lung weight (LW) [18], lung weight/body weight ratio (LW/BW) [19-22], radial alveolar count [19, 20, 23], mean alveolar length [24], relative arteriolar media thickness [24] and finally DNA content [25]. Numerous authors have attempted to established diagnostic criteria of pulmonary hypoplasia but there is still uncertainty as to which method is more reliable. Lung weight /BW with age-matched reference values established by De Paepe et al. seems to be an accurate and objective method of assessment of lung growth at postmortem examination [22]. The RAC tool to evaluate complexity of lung development determined by Askenazi et al. is useful in the saccular and alveolar phase of pulmonary growth [19].

The $\mathrm{Ki}-67$ antigen is a nuclear protein which is defined by its reactivity with monoclonal antibody from the Ki-67 clone. This antigen is preferentially expressed during all active phases of the cell cycle. Previous studies showed that Ki-67 is a useful marker for proliferative activity in the fetal and neonatal lung [26-28].

The aim of this study was to investigate expression of $\mathrm{Ki}-67$ in human fetuses with pulmonary hypoplasia compared to fetuses without pulmonary pathology and malformations of other organs used as controls.

\section{Material and methods}

The analysis comprised 149 formalin-fixed and paraffin-embedded tissue sections from the files of the Clinical Pathology Department of the Research Institute of Polish Mother's Memorial Hospital in Lodz. Tissue sections obtained from lungs during autopsies were divided into two groups: tissue sections from the lungs of 112 live born and stillborn subjects selected according to recognized pulmonary hypoplasia (Group A) and from 29 so-called "normal" control infants or fetuses with no identifiable risk factors for lung hypoplasia (Group B) selected on the basis of $\mathrm{LW} / \mathrm{BW}$ ratio. Each group was then divided into three subgroups on the basis of developmental stage of lung (A1/B1 - canalicular stage of lung growth; A2/B2 saccular stage of lung growth; A3/B3 - alveolar stage of lung growth). Assessment of $\mathrm{LW} / \mathrm{BW}$ ratio was based on the method established by De Paepe $e t$ al. [22]. The stage of lung development was evaluated adapting the method described by Langston et al. [29]. Immunohistochemistry was performed on formalinfixed and paraffin-embedded sections mounted on glass slides (4-micrometer thick sagittal sections). The pre-treatment process of deparaffinization, rehydration and epitope retrieval was performed using PT Link (Pre-Treatment Module for Tissue Specimens, DakoCytomation). Immunohistochemistry was performed using En Vision DuoFLEX Doublestain System together with Dako Autostainer Instruments
(DakoCytomation). Visualization was based on peroxidase (HRP) using DAB + as a chromogen. FLEX Monoclonal Mouse Anti-Human Ki-67 Antigen antibody was used (Ki-67 Clone MIB-1, Ready-to-Use antibody, DakoCytomation). Morphometric analysis was performed without previous knowledge of the basic data of the child (gestational age, length of survival, if any, and other anatomical diagnoses obtained during autopsies).

Morphometric analysis was performed at the light microscope level (Nikon Eclipse E-800) using ImageJ software (Java-based image processing program developed at the National Institutes of Health). Slides were evaluated under a microscope connected to the camera (Nikon DS-V2). At least 5 images were taken from each slide (each separated by one visual field, magnification $100 \times$ ) and stored on the computer's hard drive. Obtained images were selected and some of them were excluded from the analysis. In each obtained image quantitative examinations were carried out automatically using ImageJ's selection tools, working under macroinstructions written for this analysis. Differences in Ki-67 positive proliferating cells were determined in experimental and control groups with regard to developmental stage of lung growth. The results of evaluation were presented as a percentage of positive nuclei.

Student's t-test was used for comparisons between groups. Values were expressed as means \pm standard deviation (SD). The significance level was set at $\mathrm{p}<0.05$.

\section{Results}

In all cases screened for study the diagnosis of pulmonary hypoplasia was established by assessment of LW/BW ratio (lung weight : body weight ratio). To verify the correlation between proliferative growth fraction and pulmonary development, the percentage of Ki-67 positive stained nuclei in control and experimental groups was analyzed. The results of statistical analysis are presented in Table I. Pulmonary hypoplasia was diagnosed more often in male $(62.5 \%)$ as compared to female $(37.5 \%)$ infants or fetuses. Primary lung hypoplasia (without underlying abnormalities) was diagnosed in 15 cases (13\%) in this study in which secondary hypoplasia constitutes $87 \%$ of cases. In the majority of the secondary hypoplasia cases, renal/urinary tract malformations and congenital diaphragmatic hernia were diagnosed. There were statistically significant differences $(\mathrm{p}<0.05)$ between the two investigated groups in the canalicular and saccular stage of lung growth. The mean values in the control group were significantly higher (A1: 9.86\%; A2: $5.73 \%$ ) than in the case group (B1: 7.04; B2: $4.56 \%$ ). In relation to the alveolar phase of lung development there were higher mean values of growth fraction in the control group, but these differences were not sta- 
Table I. Immunoexpression of $\mathrm{Ki}-67$ in study and control groups

\begin{tabular}{|c|c|c|c|c|c|c|}
\hline & \multicolumn{2}{|c|}{ CANALICULAR PHASE } & \multicolumn{2}{|c|}{ SACCULAR PHASE } & \multicolumn{2}{|c|}{ ALVEOLAR PHASE } \\
\hline & $\begin{array}{c}\text { STUDY } \\
\text { GROUP (A1) }\end{array}$ & $\begin{array}{c}\text { CONTROL } \\
\text { GROUP (B1) }\end{array}$ & $\begin{array}{c}\text { STUDY } \\
\text { GROUP (A2) }\end{array}$ & $\begin{array}{c}\text { CONTROL } \\
\text { GROUP (B2) }\end{array}$ & $\begin{array}{c}\text { STUDY } \\
\text { GROUP (A3) }\end{array}$ & $\begin{array}{c}\text { CONTROL } \\
\text { GROUP (B3) }\end{array}$ \\
\hline $\mathrm{N}$ & 162 & 69 & 271 & 71 & 20 & 5 \\
\hline $\begin{array}{l}\text { Mean } \\
\text { value }\end{array}$ & 7.041 & 9.861 & 4.560 & 5.736 & 7.506 & 10.781 \\
\hline Min. & 0.354 & 0.183 & 0.272 & 0.309 & 1.117 & 9.433 \\
\hline Max. & 23.758 & 25.312 & 19.952 & 13.841 & 18.228 & 12.589 \\
\hline SD & 5.249 & 5.294 & 3.585 & 2.809 & 4.831 & 1.269 \\
\hline $\mathrm{P}$ & \multicolumn{2}{|c|}{$<0.05$} & \multicolumn{2}{|c|}{$<0.05$} & \multicolumn{2}{|c|}{$>0.05$} \\
\hline
\end{tabular}

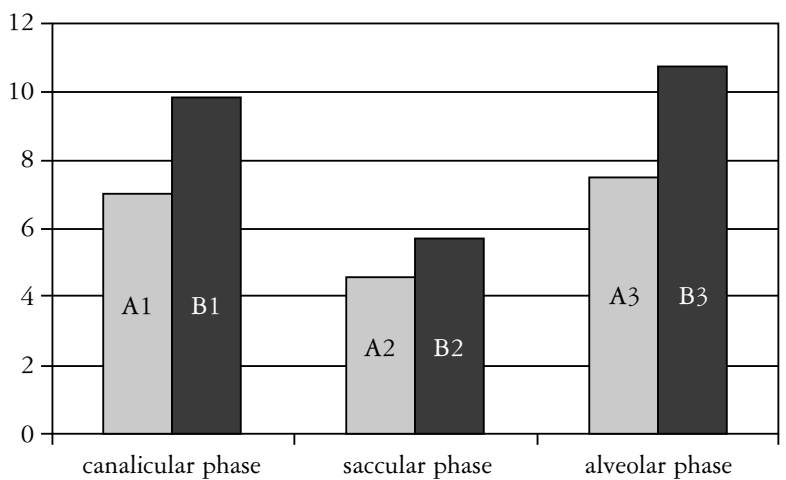

$\square$ study group $\quad \square$ control group

Fig. 1. The graph shows immunoexpression of $\mathrm{Ki}-67$ in study and control groups in relation to lung developmental stage (A1/B1 - canalicular stage of lung growth; A2/B2 saccular stage of lung growth; A3/B3 - alveolar stage of lung growth)

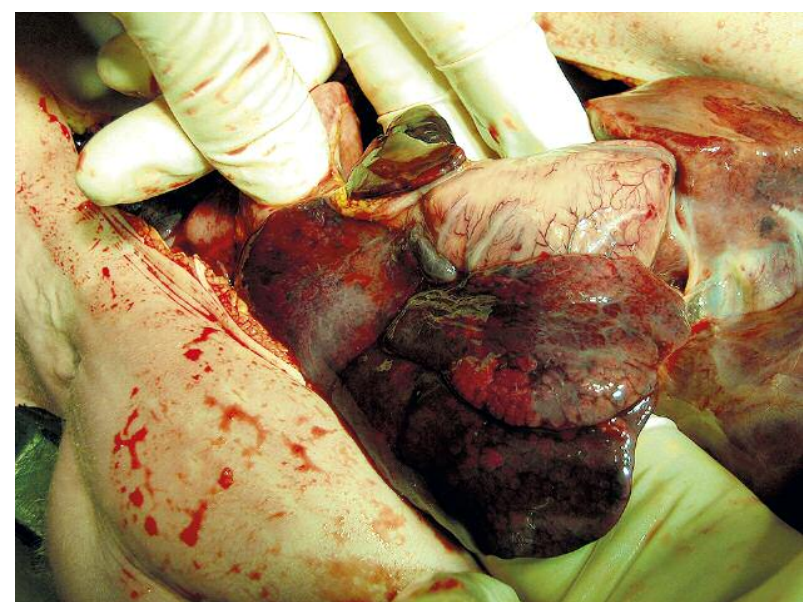

Fig. 3. Postmortem examination. Unilateral, secondary lung hypoplasia related to left-sided congenital diaphragmatic hernia. Pulmonary hypoplasia was diagnosed prenatally at 26 weeks of gestation. Female neonate died 6 hours after delivery

tistically significant. Mean growth fraction values were C1: $10.78 \%$ and C2: $7.50 \%$ of cases for the control and case group, respectively. Values of $\mathrm{Ki}-67$ positive cells

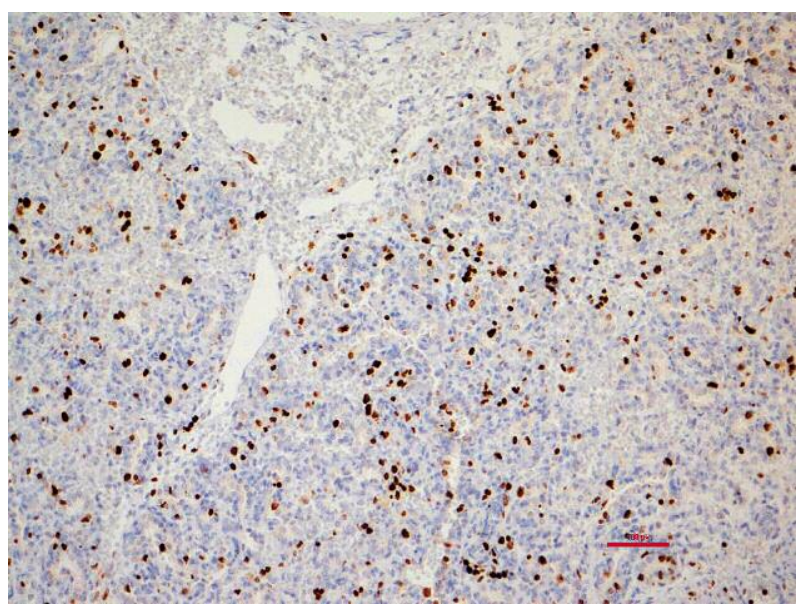

Fig. 2. Ki-67 immunoexpression in the parenchyma of hypoplastic lungs, original magnification $100 \times$

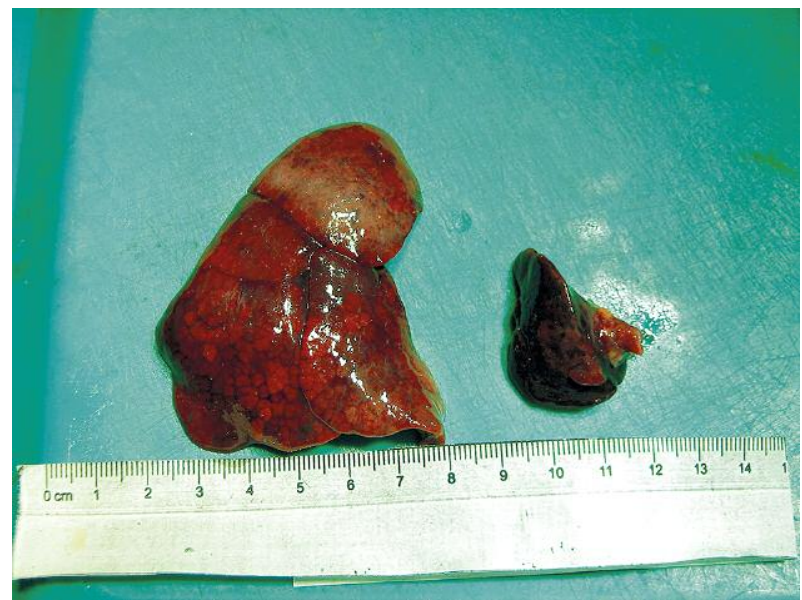

Fig. 4. Unilateral, secondary lung hypoplasia related to congenital diaphragmatic hernia. The same case as presented in Fig. 3

in the saccular stage of lung development were lower than in the canalicular and alveolar phase in both study and control groups. 


\section{Discussion}

Previously published data showed that quantification of proliferating activity can be applied in studies of lung developmental malformations based on experimental animal models [28]. In our study, immunohistochemistry was performed using an antibody against $\mathrm{Ki}-67$ as a cell proliferation marker for evaluation of growth fraction in the fetal and neonatal human lungs. So far there is only a single published investigation based on human lung examinations [27]. The study conducted by Thomas et al. revealed no significant difference in the proliferative ratios between control and hypoplastic lungs when gestational age was under 24 weeks. However, for gestational age above 24 weeks the growth fraction for controls was approximately four times higher than in the group of fetuses with pulmonary hypoplasia. The authors suggest that proliferative potential of the human lungs exists at or before 24 weeks of gestation. In the control group studied by Thomas et al. there were included 3 fetuses with conditions resulting in pulmonary hypoplasia (Arnold-Chiari malformation, abruptio placentae, renal agenesis). The previously mentioned study was underpowered as a result of the small sample size (controls: 8 cases; hypoplastic lungs: 12 cases). In addition, the improperly selected control group could affect the results.

Our findings contradict the results obtained by Thomas et al. The results presented in our study showed higher expression of growth fraction in the control group as compared to study subjects in all stages of lung development. Our study population consisted of 112 cases with pulmonary hypoplasia and 29 cases of gestational age-matched control subjects. In addition, cases with malformations potentially associated with pulmonary hypoplasia were excluded from the control group.

During histological and morphometric evaluation some interesting results were found. They support the theory that reduction in $\mathrm{Ki}-67$ immunoproliferating cells is a characteristic feature of lung hypoplasia. Moreover, our data suggest that the lung proliferative fraction is reduced in the saccular stage of pulmonary development. The results are explicable. In the saccular phase of lung growth, the basic structure of the gasexchanging unit is formed. Flattening of the acinar epithelium marks the differentiation of type II pneumocytes, from which type I pneumocytes responsible for gas exchange will be derived. During this period surfactant-producing pneumocytes mature, completing the functional maturity of the respiratory tract. The findings obtained in our investigation prove previously published data showing that in this period of lung development maturation and differentiation are the most intensive [30].

Adequate morphological and functional lung development is a critical determinant of postnatal out- come. It has been shown that advances in prenatal diagnosis of pulmonary hypoplasia have allowed in utero interventions. It seems that quantification of pulmonary hypoplasia is a useful tool in the choice of management options, including termination of pregnancy, planned delivery with intensive postnatal therapy, and fetal surgery intervention. Thomas et al. suggest that successful prenatal surgery should be performed before 24 weeks of gestation. Our findings enable us to formulate the hypothesis that in utero treatment of pulmonary hypoplasia should be performed in the canalicular or alveolar stage of lung development. In these stages the proliferative potential of human lungs for growth is the highest.

Quantification of growth fraction can be performed using manual or automatic counting of the percentage of positively stained nuclei. Previous studies revealed that data obtained using both methods were comparable. Our study was conducted using automatic morphometric analysis. Quantification of the proliferative fraction using this method turned out to be objective and fast.

In conclusion, our results indicate their usefulness to better understand the etiology of pulmonary hypoplasia and may be helpful in identifying the most appropriate moment for prenatal interventions.

\section{The authors declare no conflict of interest.}

\section{References}

1. Boyden EA. Developmental anomalies of the lungs. Am J Surg 1955; 89: 79-89.

2. Porter HJ. Pulmonary hypoplasia - size is not everything. Virchows Arch 1998; 432: 3-6.

3. Wigglesworth JS, Desai R, Guerrini P. Fetal lung hypoplasia: biochemical and structural variations and their possible significance. Arch Dis Child 1981; 56: 606-615.

4. Wigglesworth JS, Desai R. Use of DNA estimation for growth assessment in normal and hypoplastic fetal lungs. Arch Dis Child 1981; 56: 601-605.

5. Nakamura Y, Harada K, Yamamoto I, et al. Human pulmonary hypoplasia. Statistical, morphological, morphometric, and biochemical study. Arch Pathol Lab Med 1992; 116: 635-642.

6. Griffiths PD, Paley MN, Whitby EH. Post-mortem MRI as an adjunct to fetal or neonatal autopsy. Lancet 2005; 365: 1271-1273.

7. Huisman TA. Magnetic resonance imaging: an alternative to autopsy in neonatal death? Semin Neonatol 2004; 9: 347-353.

8. Jani J, Peralta CF, Van Schoubroeck D, et al. Relationship between lung-to-head ratio and lung volume in normal fetuses and fetuses with diaphragmatic hernia. Ultrasound Obstet Gynecol 2006; 27: 545-550.

9. Jani JC, Nicolaides KH, Gratacós E, et al. Fetal lung-to-head ratio in the prediction of survival in severe left-sided diaphragmatic hernia treated by fetal endoscopic tracheal occlusion (FETO). Am J Obstet Gynecol 2006; 195: 1646-1650.

10. Jani J, Keller RL, Benachi A, et al. Prenatal prediction of survival in isolated left-sided diaphragmatic hernia. Ultrasound Obstet Gynecol 2006; 27: 18-22.

11. Ruano R, Aubry MC, Dumez Y, et al. Predicting neonatal deaths and pulmonary hypoplasia in isolated congenital diaphragmatic 
hernia using the sonographic fetal lung volume-body weight ratio. AJR Am J Roentgenol 2008; 190: 1216-1219.

12. Wigglesworth JS, Desai R, Guerrini P. Fetal lung hypoplasia: biochemical and structural variations and their possible significance. Arch Dis Child 1981; 56: 606-615.

13. Wigglesworth JS, Desai R. Use of DNA estimation for growth assessment in normal and hypoplastic fetal lungs. Arch Dis Child 1981; 56: 601-605.

14. Sander K. Ernst Haeckel's ontogenetic recapitulation: irritation and incentive from 1866 to our time. Ann Anat 2002; 184: 523-533.

15. Daniels CB, Orgeig S, Sullivan LC, et al. The origin and evolution of the surfactant system in fish: insights into the evolution of lungs and swim bladders. Physiol Biochem Zool 2004; 77: 732-749.

16. Swischuk LE, Richardson CJ, Nichols MM, Ingman MJ. Bilateral pulmonary hypoplasia in the neonate. AJR Am J Roentgenol 1979; 133: 1057-1063

17. Wigglesworth JS. Pathology of the lung in the fetus and neonate, with particular reference to problems of growth and maturation. Histopathology 1987; 11: 671-689.

18. Gruenwald P, Hoang Ngoc M. Evaluation of body and organ weights in perinatal pathology. I. Normal standards derived from autopsies. Am J Clin Pathol 1960; 34: 247-253.

19. Askenazi SS, Perlman M. Pulmonary hypoplasia: lung weight and radial alveolar count as criteria of diagnosis. Arch Dis Child 1979; 54: 614-618.

20. Emery JL, Mithal A. The number of alveoli in the terminal respiratory unit of man during late intrauterine life and childhood. Arch Dis Child 1960; 35: 544-547.

21. Wigglesworth JS, Desai R, Guerrini P. Fetal lung hypoplasia: biochemical and structural variations and their possible significance. Arch Dis Child 1981; 56: 606-615.

22. De Paepe ME, Friedman RM, Gundogan F, Pinar H. Postmortem lung weight/body weight standards for term and preterm infants. Pediatr Pulmonol 2005; 40: 445-448.

23. Betz P, Nerlich A, Bussler J, et al. Radial alveolar count as a tool for the estimation of fetal age. Int J Legal Med 1997; 110: 52-54.

24. Heerema AE, Rabban JT, Sydorak RM, et al. Lung pathology in patients with congenital diaphragmatic hernia treated with fetal surgical intervention, including tracheal occlusion. Pediatr Dev Pathol 2003; 6: 536-546.

25. Wigglesworth JS, Desai R. Use of DNA estimation for growth assessment in normal and hypoplastic fetal lungs. Arch Dis Child 1981; 56: 601-605.

26. Cangiarella J, Greco MA, Askin F, et al. Congenital cystic adenomatoid malformation of the lung: insights into the pathogenesis utilizing quantitative analysis of vascular marker CD34 (QBEND-10) and cell proliferation marker MIB-1. Mod Pathol 1995; 8: 913-918.

27. Thomas PA, Durbin J, Langston C, et al. Growth fraction determination in pulmonary hypoplasia using Ki-67 (MIB-1) antibody. Pediatr Pathol Lab Med 1996; 16: 745-753.

28. Olson JC, Kurek KC, Mehta HP, et al. Expansion thoracoplasty affects lung growth and morphology in a rabbit model: a pilot study. Clin Orthop Relat Res 2011; 469: 1375-1382.

29. Langston C, Kida K, Reed M, Thurlbeck WM. Human lung growth in late gestation and in the neonate. Am Rev Respir Dis 1984; 129: 607-613.

30. Marszałek A, Biczysko W, Wasowicz M. Development of the fetal and newborn lung - morphometric studies (rat model). Pol J Pathol 1999; 50: 277-288.

\section{Address for correspondence}

Monika Dzieniecka PhD

Department of Clinical Pathomorphology

Research Institute of the Polish Mother's Memorial Hospital 281/289 Rzgowska St., 93-338 Lodz, Poland

tel. +48422711285

e-mail: m.dzienieck2@gmail.com 